\title{
Study on Teaching Strategies of College English Flipped Class Based on MOOC
}

\author{
Xiangmin Li \\ Zhongyuan University of Technology, Zhengzhou, Henan, China, 450007
}

Keywords: Teaching Strategies, Flipped Class, MOOC

\begin{abstract}
With the rapid development of information technology, there are many emerging interactive teaching modes in the education system. In the new era, the traditional college English teaching is faced with many problems. The traditional college English teaching model cannot adapt to the development needs of the times. Thus, it is necessary to strengthen the reform in college English teaching and to achieve the goal of teaching information technology and college English Integration, strengthen the use of "flip classroom" teaching mode, so as to effectively promote the reform of college English teaching and innovation, improve the quality of college English teaching, and constantly improve the course content. Since the overall quality of students play an important role in the teaching. Based on this, the author conducted an in-depth study on college English "flip classroom" under the MOC class and put forward specific teaching strategies.
\end{abstract}

\section{Introduction}

In college teaching system, College English as an important basic course content, plays an important role in training qualified personnel in colleges and universities. At present, college English classroom teaching generally adopts the teaching method of teaching in large classes. There are a large number of students. It seems that it is difficult to mobilize students' enthusiasm without the combination of informationization, and it is impossible to organize learning to carry out teaching activities, resulting in inefficient teaching of actual teaching and difficulty in effective teaching Improve students' English level. The main problems are as follows: When teachers choose and set the curriculum content, they do not fully consider the development demands of students, the content of the courses they choose to apply is too old, and the students lack interest in learning. Course teaching system is too monotonous, the lack of a reasonable logic, curriculum assessment and evaluation of the way not scientific and reasonable. With the rapid development of information technology, the era has come into full play. In the college English teaching under the era, it is necessary to strengthen the application of the teaching mode of "flip the classroom" to break the limitations of the traditional classroom teaching and adopt advanced informatization Technology to make teaching video content, to attract students 'attention, to mobilize students' interest in learning in order to speed up the process of knowledge internalization, which is also an important breakthrough in the current college English reform and development. First, flip the classroom and MOOC theory (a) flip the classroom Since the twenty-first century, the traditional teaching mode of continuous innovation and development, the famous American professor Michael Treglia and Glenn Platt and others co-developed a successful "flip classroom" teaching mode, Then Jonathan Bergmann and Aaron teachers applied the teaching method of "flip classroom" in the chemistry class teaching and got a good teaching result. This flip classroom teaching mainly refers to the use of classroom teaching PPT presentation files and teaching videos, which play a detailed explanation of the role of knowledge content. After class, the teaching videos can be uploaded to the teaching website, so that some students unable to enter the classroom can watch the teaching videos and learn the knowledge contents on the network. Flip classroom teaching mode overturned the traditional classroom teaching mode, including teaching content, teaching subjects and teaching methods flip, students can learn the course content under the class, do not need to enter the classroom, when students grasp the relevant course content, the homework exercises Brought into the classroom for discussion, this can improve teaching efficiency. In overturned classroom teaching, students mainly conduct teaching activities mainly with more flexible and convenient 
teaching methods to speed up the efficiency of problem solving.

\section{A Summary of College English Flipped Class Implementation under the Background of MOOC}

MOOC and flip class as a teaching medium under the network age, the two effectively combined to help college English teaching. It realizes the remedies of the limitations of traditional teaching methods, helps students to better understand and grasp the knowledge of grammar vocabulary and so on, and realizes the goal of improving students' English comprehensive ability. The MOU and college English flip classroom together, more conducive to student acceptance. Taking college English course teaching as an example, we must take a ring-shaped construction model in the teaching construction and implementation of the flip classroom. Therefore, the college English flip classroom can be divided into four stages. The first phase is to experience participation. The second stage is conceptual exploration, the third stage is the construction of meaning, the fourth stage is to show the application. The introduction of MOOC on the basis of overturning the classroom makes the teaching model highlight two parts. In the class stage, teachers guide students to quickly complete the relevant tests, ask questions and solve problems to achieve the internalization of knowledge.

\section{The Constraints of College English Flipped Classroom Teaching under the MOOC}

In the era of Internet information, in order to improve the efficiency of teaching courses, resulting in resources. Since the advent of self-resourced resources, it has seriously affected college English education. Much of the voices of questioning exist in the application of MOOC, mainly because of the very low passing rate of MOCC. According to a survey conducted by relevant professors in the United States, it is found that the passing rate of MOU course resources is generally below 50\%, which does not meet the design expectation. Therefore, in college English teaching, we must constantly develop and apply the resources of mousse and constantly optimize and adjust the teaching methods of mural courses.

Much of the $\mathrm{Mu}-\mathrm{Mu}$ curriculum is used in foreign higher education. Much of the $\mathrm{Mu}-\mathrm{Mu}$ resources are designed and published by well-known foreign teachers. There is a big difference between the teaching of foreign English and the teaching of College English in China, Big difference. For example, in the "science and technology English writing" of resources, which mainly describes the content of academic writing related courses, these courses are not suitable for the current university English teaching needs. In addition, the English level of college students in our country is generally lower than that of foreign students, so we cannot correctly understand the contents of foreign language courses. At present, there are very few resources for released and available for use on our MOOC platform.

The main evaluation subjects of MOOC are students, teachers and education departments. There are great differences in the evaluation methods adopted by the three evaluation subjects. Students in the evaluation of MOOC, mainly by questionnaires and group interviews in two ways, a comprehensive evaluation MOOC course content, teaching methods and the ability of teachers. However, during the course evaluation, teachers mainly evaluate self-teaching ability, compare and evaluate the teaching effect of MOU, and evaluate the teaching of MOU scientifically and reasonably. In the evaluation of MOOC, the education department mainly evaluates the MOUC's application effect and deeply explores the MOOC's credit mechanism and application mechanism. At present, Mu-class online testing, including multiple-choice questions and fill in the blank content, the lack of practical application content, it cannot be a reasonable evaluation of application skills. Therefore, it is necessary to improve and perfect the MOU evaluation system in order to enhance the fairness and rationality of the evaluation mechanism.

Adopting the overturning classroom teaching mode in college English teaching under the Moutai era, we must improve the hardware facilities and strengthen the modern information construction in colleges and universities. At present, although the campus network is covered in many universities 
and colleges, there is not enough digital equipment and a complete learning exchange network platform. At the same time, college English teachers' teaching philosophy is too traditional. Without professional information network technology, lack of firm confidence in educational reform, teachers cannot reasonably produce teaching videos based on the contents of the course, which seriously affects the quality of overturning classroom teaching.

\section{Teaching Strategies of College English Flipped Classroom Based on MOOC Resources}

In the era college English using flip classroom teaching mode, we must change the traditional teaching methods, based on the resources give full play to the role of online teaching platform, to achieve flip classroom teaching. In the current college English teaching, not only students' knowledge of books should be cultivated, but also students' comprehensive abilities and English qualities should be cultivated. Students should be able to use English knowledge to socialize, solve practical problems and develop students' English thinking ability. Teachers must give full play to the advantages of resources, in order to enhance students' ability to practice English. At the same time, with the rapid popularization of Internet intelligent devices, teachers need to give full play to the role of intelligent electronic devices, using mobile teaching methods, implementing personalized teaching, carrying out teaching activities according to individual needs of students, enabling students to receive classes anytime, anywhere Knowledge, make up for the shortcomings of the traditional classroom teaching, mobilize students' interest in independent study. In addition, from the aspects of listening, speaking, reading and writing of college English, we should comprehensively develop students' English proficiency so as to enable students to reach the level of students in English-speaking countries and use MOOC to create a good English culture for students.

In the process of overturning classroom teaching, computer information technology plays a crucial role. Only by relying on computer network equipment can we effectively turn over classroom teaching. Therefore, it is necessary to build effective informatization learning resources in college English, and then upload the learning resources to relevant websites so that students can download and watch teaching resources at any time. Much resources in the main contains a variety of learning plans, problem-solving methods, skills and online homework and testing, construction of a comprehensive teaching knowledge network, so that students can continue to expand learning. Flip classroom teaching content must be closely around the content of the knowledge point, the video is short and pithy-based, in the English teaching video, you need to include a clear vocabulary, grammar points and thematic content in the course before, during and after the three stages We need to implement the interactive links and arrange reasonable after-school assignments in order to cultivate students' abilities of listening, speaking, reading, writing and translating. At the same time, in college English teaching, teachers must constantly encourage students to read English culture and knowledge related books, learn English language features, familiar with English culture, video courses need to include a variety of English content.

Currently, major institutions in our country have provided "college English" course, and for different professional provides the corresponding professional English. Although many colleges carry out the college English MOOC course, the MOOC course is only open to our students and is not open to students from other colleges and universities. As a result, the quality of college English teaching cannot be improved. In order to realize the college English flip classroom teaching in major universities in China, it is necessary to break the restrictions of the regions and institutions, strengthen the development and design of large-scale online open courses, strengthen exchanges and cooperation among major institutions and organize the design of English MOU course. However, in the design of courses, we must pay attention to the course video design, interactive design and evaluation design, design a reasonable evaluation method, so that students, teachers and education management departments can better evaluate, and constantly reflect and improve College English flip classroom teaching the way. 


\section{Conclusions}

Based on the MOOC flip classroom teaching model in the ascendant, in the process of combining with the college English teaching has obvious advantages, with the students as the focus of practical study, combined with college English teaching content and teaching tasks, advocating micro-curricular, small testing and real-time answer teaching model to achieve the enrichment of Therefore, it is necessary to innovate the teaching mode, pay attention to teaching interaction, introduce the encouragement mechanism, focus on the improvement of students' attention in class and Teaching efficiency improvement.

\section{Acknowledgements}

Fund Project: Study on SPOC Open Online Courses Construction and Application Research in Textiles Universities Supported by "The Light of Textile" Higher Education Teaching Reform Project of China Textile Industry Association (Project Number: 2017BKJGLX033)

\section{References}

[1] Liu Mangu. Study on Teaching Model of "Flip Classroom" under the Vision of Muclassology [J]. Journal of Guangdong Polytechnic Normal University, 2016, (07): 125-132.

[2] Qin Xiaohong. Research on the Teaching Mode of College English Flip Class Based on Mu-mo Resources [J]. Journal of Jilin Institute of Education, 2016, (02): 74-76.

[3] Pu Zhengfang. Based on "Mousu" environment college English flip classroom teaching mode [J]. Honghe University, 2015, (05): 111-113.

[4] Zhang Mulin, Sun Xiaojun. Research on the Flip Classroom Teaching Model Based on MOOC Taking College English Follow-up Course as an Example [J]. Modern Education Technology, 2015, (08): 81-87.

[5] Gao Yuxia. Study on the Teaching Mode of College English Flip Class in the Perspective of MOOCes [J]. CAI ZHI, 2016, (18): 21. 